\title{
Locus of control and involvement in videogaming
}

Lloyd, J.; Frost, S.; Kuliesius, I.; Jones, C.

Uncorrected proof, as accepted for publication in New Media and Society on 11.01.19. 


\begin{abstract}
An external locus of control (feeling low personal control over one's life) has been linked with excessive/addictive behaviours, including problematic videogaming. The current study sought to determine whether this is driven by the opportunity for greater control over one's environment within a videogame. Participants ( $n=252,59 \%$ males) completed a traditional locus of control scale (Levenson, 1981), alongside a modified version assessing in-game feelings of control. Multiple linear regression analyses indicated that feeling less under the control of powerful others in-game than in the real world was a significant predictor of gaming frequency (standardized beta $=.31, \mathrm{p}<.0005$ ), while feeling comparatively more internal control in-game than in real life significantly predicted problematic gaming (standardized beta $=.17, \mathrm{p}=.02$ ). This demonstrates that locus of control in-game can diverge from that experienced in the real-world, and the degree of divergence could be a risk factor for frequent and/or problematic gaming in some individuals.
\end{abstract}

Keywords: Problem gaming; locus of control; videogames; enjoyment; videogame genre; addiction 


\section{Introduction}

Videogame play, hereafter 'gaming', is an increasingly popular form of entertainment (Ipsos MediaCT, 2014), and it can have a range of positive outcomes (Adachi and Willoughby, 2017). However, it has also received negative attention, and problematic gaming has been explored in particular within the online gaming context, where scales based on the DSM-5 criteria for addictive disorders have been developed to assess it (Demetrovics et al., 2012). It is characterised by preoccupation with gaming, and excessive participation, with negative impacts on other aspects of one's life (e.g. social interactions), and difficulty cutting down or stopping the activity (Demetrovics et al., 2012). While debate continues over whether 'gaming disorder' should be recognized as a clinical condition (Aarseth et al., 2016; Griffiths et al., 2016; Kuss et al., 2017), it is generally accepted that some people do experience problems related to excessive gaming, including psychological, social, and physical consequences (Subramaniam et al., 2016).

Given the array of both risks and benefits potentially associated with gaming, and its popularity, it is important to learn more about the factors associated with both positive and negative gaming experiences. One correlate of problematic gaming is an external locus of control' (KoO, 2009), i.e. feeling that one's life and experiences are governed by chance and other external forces (such as other, powerful people), and that one has little personal control over what happens (Koo, 2009; Lam and Mizerski, 2005). High external locus of control has been linked with a number of problematic or excessive behaviours including 'Internet addiction' (Chak and Leung, 2004; İskender and Akin, 2010), use of a mobile phone at inappropriate times (Li et al., 2015); smartphone dependency (Park et al., 2013);

excessive use of instant messaging (Hou et al., 2017); gambling (Browne and Brown, 1994) and substance misuse (Haynes and Ayliffe, 1991). This could indicate that external locus of control's link to problematic gaming is explained by an individual's (perceived) lack of ability to moderate their behaviour resulting in a tendency to engage excessively in the enjoyable activity, despite negative consequences.

However, it is also possible that external locus of control is linked with gaming because people who do not feel a strong sense of control over their own day-to-day lives are 
particularly drawn to videogames, where they may feel a greater sense of control. A number of structural characteristics common to most videogames are likely to afford an enhanced sense of control, from the ability to select one's character (which has been linked with sense of control and enjoyment) (Rogers et al., 2016), to the visibility of explicit metrics charting one's progress towards a goal; the ability to re-attempt difficult tasks after failure; and the typical presence of frequent small, attainable goals that bring a relatively predictable reward (King et al., 2010). The simplification of goals and the clarity of wins and losses, along with opportunity to develop and display mastery have also been identified as important features that make games 'fun', (Castronova, 2008a), all of which are also intuitively, closely linked with feelings of control.

The idea that this 'controllability' of games might attract people who feel a lack of control in the real world would be broadly consistent with the finding that the link between gaming motivations such as escapism and enjoyment, and the intention to play videogames, was stronger in people with a higher external locus of control (Koo, 2009). If we suppose that experiencing higher internal control in-game is one of the mechanisms by which gaming provides a sense of escape from one's day-to-day reality, then other studies that have found links between escape-related gaming motivation and excessive gaming (Dauriat et al., 2011; Kuss et al., 2012), would also align with this theory. The finding that external locus of control was associated with immersion in a virtual reality online game (Murray et al., 2007) also suggests that people with low feelings of control in real life may find games particularly engaging - again, perhaps because of the increased potential to feel internal control.

The current study sought to explicitly investigate the links between locus of control and videogaming. Levenson (1981) identified three dimensions of locus of control, referred to as 'internality' (feeling that the outcomes one experiences are primarily influenced by one's own actions), 'powerful others' (feeling that one's fate is controlled by powerful people or organisations); and 'chance' (feeling that one's experiences are driven by chance, luck or fate). We used the traditional 'real-life' version of Levenson's (1981) locus of control scale alongside a version that we modified to allow us to measure individuals' perceived locus of control within the videogame environment. This allowed for an examination of whether ingame feelings of control compare with one's real-life feelings of control, and of how both ingame and real-world locus of control relate to gaming involvement, gaming enjoyment, and 
problematic gaming symptoms. In order to gain a full picture of gamers' involvement, it is necessary to consider both intensity of play (e.g. frequency or duration); and problematic play, as they are distinct measures, affording different information; Király et al. (2017) found, for example, that time spent gaming was only mildly correlated with problematic gaming scores, and that the latter, but not the former, were associated with psychiatric symptoms (Király et al., 2017).

Our first hypothesis $(\mathrm{H} 1)$ was that we would find external locus of control on the standard, real-world version of the scale to be associated with problematic gaming, and possibly gaming frequency, in line with previous studies that have found various addictive/excessive behaviours to be linked with greater external locus of control (e.g. İskender and Akin, 2010). We had two divergent hypotheses regarding scores on the game-related version of the locus of control scale. If an individual's locus of control within the game simply mirrors their locus of control in the real-world, we predicted that external locus of control on the in-game version of the scale would also be positively associated with problematic gaming $(\mathrm{H} 2)$, for the same reasons described relating to hypothesis 1 . On the other hand, if videogames are alluring to people whose real-world locus of control is highly external because they offer the opportunity to experience a more internal locus of control in-game, we expected that this would be apparent in discrepancies between people's in-game and real-world ratings of locus of control (H3). If H3 is the case, and individuals' locus of control in-game differs from that in the real world, we predicted that higher ratings of internal locus of control in-game would be linked with gaming enjoyment $(\mathrm{H} 4)$, and that internal, rather than external, locus of control in-game would predict problematic gaming (and possibly gaming frequency) scores $(\mathrm{H} 5)$, by virtue of creating an environment in which people wish to spend a lot of time.

Because 'gaming' is such a heterogeneous activity, where different game genres are associated with different motivators (Koo, 2009; Laconi et al., 2017), we also asked participants to indicate their preferences for a range of game genres (e.g. role-play-game; first-person shooter) and modes (single player and multi-player; online and offline), to allow us to explore whether there are differences in the extent to which people with high external locus of control favour different types of game and/or different modalities of play. As there has been, to our knowledge, no previous research specifically investigating this question, we 
made no a priori hypotheses about which games would be associated with locus of control scores.

\section{Method}

\section{Design}

The current study used a cross-sectional, quantitative web-based survey to collect data on a convenience sample of participants' positive and negative experiences of gaming, their locus of control (in-game and in the real world); their game preferences; and their gaming frequency.

\section{Recruitment and Participants}

The survey was available in English, and data collection took place over a 4-month period from March to July, 2018. The survey link was circulated to a group of approximately 30 undergraduate students during a research module data-collection session, and was also advertised (concurrently) online, through posts on gaming-specific forums (a Minecraft forum and a forum for players of online roleplay games); gaming and research related areas of general discussion forums (Reddit and Imgur); and social media (Twitter and Facebook, via the researchers' networks). The advertisement specified that participants needed to be aged 18 or older, and to have had at least some experience of videogaming (which could include console-based and/or mobile gaming, of any type, with no specified minimum recency or frequency of participation). No incentives were offered for participation. A total of 252 participants (100 female; 148 male; 4 other/prefer not to say) with a mean age of 28.7 (SD 11.4) years, completed the survey.

\section{Materials}

\section{Locus of control (real-world)}

Traditional (real-world) locus of control was measured with Levenson's (1981) locus of control scale. This is comprised of three subscales; 'internality' (with items such as 'I can pretty much determine what will happen in my life'), 'powerful others' (e.g. 'I feel like what happens in my life is mostly determined by powerful people'), and 'chance' (e.g. 'when I get what I want, it's usually because I'm lucky'), with 8 items per subscale, and responses made on a 6-point Likert scale (from 'strongly disagree' to 'strongly agree'). Items were scored as 
per the author's instructions (http://www.hannalevenson.com/ipcscales.pdf), producing scores of 0-48 for each subscale. The reliability and validity of the scale are well-established (Levenson, 1981), including in recent studies (Kourmousi et al., 2015; Maroufizadeh et al., 2016).

\section{Locus of control (game-world)}

Locus of control within videogames was measured with an adapted version of Levenson's aforementioned scale. In this version, all statements were revised to refer to feelings when playing a videogame (by inserting the words 'in a game' and/or removing the words 'in my life'; e.g. 'when I get what I want in a game, it's usually because I'm lucky'). Otherwise, the wording remained exactly the same as the original items. We did not give participants guidance on how to interpret the questions in relation to the game world, but it is likely that as with the real world, ratings on items within the subscale of 'internality' (e.g. 'When I get what I want in a game, it's usually because I worked hard for it') were based upon judgements of the importance of personal skill and effort. Ratings on several items within the 'chance' subscale (e.g. 'when I get what I want in the game it is usually because I am lucky') may be made in much the same way as real-world judgements of chance, and some (e.g. 'I have often found what is going to happen in a game, will happen') could also reflect opinions on pre-programmed game features. Ratings of the importance of powerful others (e.g. 'getting what I want in a game requires pleasing those above me,' are likely based on feelings about other gamers within competitive or collaborative games, which could include both formal social structures (e.g. guilds) and more informal hierarchies based on skill or experience levels.

\section{Problematic gaming}

Problematic gaming was measured with the 18-item 'Problematic Online Gaming Questionnaire (POGQ)' (Demetrovics et al., 2012), which has been widely-used, and has robust psychometric properties (Király et al., 2015). For our purposes, the term 'online gaming' was replaced throughout with 'videogaming', as we were interested in both on- and offline gaming. Responses were on a 5-point Likert scale (from never to always), to questions such as 'how often do you fail to meet up with a friend because you were gaming?', and summed to give a total score from 18-90. The scale covers six domains; 
preoccupation, overuse, immersion, social isolation, interpersonal conflicts, and withdrawal related to gaming.

\section{Positive gaming experiences}

Positive experiences of gaming were measured with a selection of items from the 'Game Experience Questionnaire' (IJsselsteijn et al., 2013). The full scale consists of 81 items, with many subscales, concerned with experiences such as flow, immersion, and tension, but for this study we selected the sub-scales comprised of items related to positive experiences. This included five items rating positive affect experienced while gaming, which ask participants to rate their agreement (on a 5-point Likert scale) with the statements; 'I feel content'; 'I find it fun;' 'I feel happy'; 'I feel good'; and 'I enjoy it'; and six items rating the extent to which participants 'feel revived'; 'feel a sense of victory'; 'feel energised'; 'feel satisfied'; 'feel powerful'; and 'feel proud', when they 'have just finished playing a videogame'. While precise psychometric properties for the scale have not been published, they are reported to be robust (Norman, 2013) and the items have good face validity for assessing positive gaming experiences.

\section{Game genre preferences}

Game genre preferences were measured with an adapted version of the 'Game Preferences Questionnaire (GPQ)' (Manero et al., 2016), a comprehensive and recent instrument (important, as it lists currently available game titles as examples of genres), which asks participants to rate their preference for 9 genres of game on a 7-point Likert scale, ranging from 'strongly dislike', to 'strongly like', and asks them to rate their overall gaming frequency on a single item with a 7-point Likert scale, with anchor points of 'never' and 'daily' at either end. We adapted the scale to ask participants to rate their preferences for each genre twice; once for multi-player and once for single-player versions. The Likert scale was also updated to consist of 8 points, with the extra point being used to indicate that the participant has never played the game genre in question.

\section{Procedure}

Participants completed the survey online (through Qualtrics) after reading an information sheet and providing digital consent (by ticking a series of boxes), and were presented at the 
end with a debrief page containing contact details for a general mental health support site. Ethical approval for the study was obtained from the University of Wolverhampton Psychology Ethics Committee. The five scales described above were presented in randomized blocks, along with items asking participants to state their age and gender (this was the only demographic information collected). The survey software was set to prohibit multiple responses from the same IP address, in order to make it difficult for any individual with malicious intent to submit multiple disingenuous responses.

\section{Statistical analysis}

We used confirmatory factor analysis (CFA) and Cronbach's alpha calculations to assess the psychometric properties of the two versions of the locus of control scales. The fit of the CFA models was assessed using $\chi 2$ test, goodness-of-fit index; comparative fit index (CFI), and root mean square error of approximation.

We then compared scores across the real-world (RW) and game-world (GW) on each of the three subscales (in order to address hypothesis 3 ). We then carried out series of multiple linear regressions; the first tested whether real-world and in-game locus of control scores predicted gaming frequency (model $1 \mathrm{a}$ ) and problem gaming (model $1 \mathrm{~b}$ ), respectively (addressing hypotheses 1 and 2). Problem gaming scores did correlate with gaming frequency ( $N=235, r=.362, p<.0005)$, but only modestly, so both variables were retained as separate measures throughout the analysis.

Because several of our hypotheses related to the prediction that gamers may feel less external (and more internal) control within a game environment than in the real world, and because we found only a relatively modest level of correlation between game-world and real-world scores, the next set of regressions used difference scores. Scores on the realworld version of the internality subscale were subtracted from scores on the in-game version, to give an indication of how much more internality an individual felt in-game (compared with in the real world); difference scores were also calculated in the same way for the chance and powerful others subscales.

The first of the regressions using these difference scores tested whether they predicted gaming frequency (model 2a) and problem gaming (model 2b) (addressing hypothesis 5). We then tested whether the difference in locus of control scores between the real-world 
and the game-world predicted positive feelings when gaming (model 3a) and positive feelings post-gaming (model 3b) (addressing hypothesis 4). Next, we included the difference scores (for in-game versus real-world locus of control), and gaming enjoyment scores, in the same models, to determine whether locus of control information was still predictive of gaming involvement when entered alongside basic measures of gaming enjoyment (models $4 a$ and $4 b)$. Finally, we carried out three regressions to see whether specific gaming genres predicted in-game locus of control on each of the three subscales (models $5 a, 5 b$, and $5 c$ ).

For each of the regressions, VIF and tolerance values were inspected and no issues with multi-collinearity were identified, and inspection of residuals indicated homoscedasticity. Potentially influential outliers among the residuals were identified by plotting Cook's distance against leverage, and where they were identified, the cases were inspected to check for any obvious errors in the data. As this process revealed no obvious reason to doubt the veracity of the cases, all values were retained in calculating the statistics reported in tables 4-10.

Squared semi-partial correlation values $\left(s r^{2}\right)$, are included in tables 4-10, as they are a useful standardized measure of effect size, indicating the amount of unique variance explained by each predictor (Dudgeon, 2016; Tabachnik, B. G. and Fidell, 2001).

Data analysis was carried out in SPSS v.24. and AMOS.

\section{Results}

\section{Participant characteristics}

Of the 252 participants who completed the survey, 100 were female, 148 male, and 4 other/preferred not to say. The mean age was 28.7 (SD 11.4) years. Mean gaming frequency score was 5.42 (SD 1.81), with the scale ranging from 1 (never) to 7 (daily). Scores on the subscale of the Gaming Experience Questionnaire referring to positive feelings while gaming were 20.36 (SD 3.60) out of a possible maximum of 25 , and scores on the subscale referring to positive feelings post-gaming were 19.01 (SD 5.60) out of a possible maximum of 30. Mean scores on the problematic gaming questionnaire were 36.53 (SD 10.67), ranging from 18-74, with the average respondent well below the suggested cut-off of 65 (out of a maximum of 90) for 'problematic gaming'. Table 1 summarises the sample's preferences for 
the different game genres, as percentage who liked, disliked, and were 'neutral' towards each one, along with the proportion who had never played them. There were a broad range of preferences, and across almost all genres, over $80 \%$ of the sample had some experience of playing within that genre, and most respondents were either neutral towards, or liked, each genre.

Table 1: Summary of game genre preferences

\begin{tabular}{|c|c|c|c|c|c|}
\hline Game genre & Mode & Never played & Dislike & Neutral & Like \\
\hline \multirow{2}{*}{$\begin{array}{l}\text { First-person } \\
\text { shooter }\end{array}$} & Single player & $9.4 \%$ & $17.7 \%$ & $7.1 \%$ & $65.8 \%$ \\
\hline & Multi-player & $12.6 \%$ & $26.2 \%$ & $6.7 \%$ & $54.3 \%$ \\
\hline \multirow[t]{2}{*}{ Adventure } & Single player & $10.6 \%$ & $10.2 \%$ & $9.8 \%$ & $69.2 \%$ \\
\hline & Multi-player & $22.0 \%$ & $28.4 \%$ & $15.1 \%$ & $34.2 \%$ \\
\hline \multirow[t]{2}{*}{ Music } & Single player & $11.8 \%$ & $29.3 \%$ & $16.1 \%$ & $42.9 \%$ \\
\hline & Multi-player & $15.5 \%$ & $24.2 \%$ & $14.7 \%$ & $45.7 \%$ \\
\hline \multirow[t]{2}{*}{ Fighting } & Single player & $16.5 \%$ & $29.2 \%$ & $17.3 \%$ & $37.0 \%$ \\
\hline & Multi-player & $19.4 \%$ & $28.1 \%$ & $14.2 \%$ & $38.3 \%$ \\
\hline \multirow[t]{2}{*}{ Quiz } & Single player & $7.9 \%$ & $17.0 \%$ & $17.8 \%$ & $57.3 \%$ \\
\hline & Multi-player & $17.0 \%$ & $18.1 \%$ & $15.8 \%$ & $49.1 \%$ \\
\hline \multirow[t]{2}{*}{ Strategy } & Single player & $15.0 \%$ & $10.3 \%$ & $9.9 \%$ & $64.8 \%$ \\
\hline & Multi-player & $23.7 \%$ & $17.7 \%$ & $13.8 \%$ & $44.7 \%$ \\
\hline \multirow[t]{2}{*}{ Sports } & Single player & $10.6 \%$ & $28.7 \%$ & $13.8 \%$ & $46.8 \%$ \\
\hline & Multi-player & $15.8 \%$ & $31.2 \%$ & $11.1 \%$ & $41.9 \%$ \\
\hline \multirow[t]{2}{*}{ Roleplay game } & Single player & $13.0 \%$ & $4.0 \%$ & $9.1 \%$ & $73.9 \%$ \\
\hline & Multi-player & $12.7 \%$ & $18.4 \%$ & $14.7 \%$ & $54.1 \%$ \\
\hline Social \& casual & $\begin{array}{l}\text { Co-located multi- } \\
\text { player }\end{array}$ & $6.7 \%$ & $6.0 \%$ & $7.9 \%$ & $79.4 \%$ \\
\hline
\end{tabular}


The Cronbach's alpha of the locus of control subscales ranged from .61 to .81 for both the original and the gaming versions, as summarised in Table 2 . While .61 is somewhat low, this is comparable with reliability of the scale reported in other recent studies (e.g. .56 to .67 in Maroufizadeh et al., 2016). Confirmatory factor analysis demonstrated that the original three factor model of Levenson's locus of control scale was a reasonably acceptable fit to the data ( $\chi 2$ test was significant at $\chi 2=509.2, d f=249, p<.05$; but this is unsurprising due to sensitivity of this statistic to sample size). Other measures of fit were also close to acceptable: $\chi 2 / \mathrm{df}=2.045$; goodness-of-fit index $=.848 ; \mathrm{CFI}=.834$, root mean square error of approximation $=.066$ (confidence intervals $=.57-.74)$. A confirmatory factor analysis of the gaming version of the scale $(n=234)$ indicated that this novel version also had a close to acceptable fit to the original model's three factor solution. The chi-square test was significant at $\chi 2=423.4(n=249), p<.05$, but again, this is unsurprising due to sensitivity of this statistic to sample size. Other fit indices were; $\chi 2 / d f=1.7$; goodness-of-fit index $=.970$; $\mathrm{CFI}=.863$, root mean square error of approximation $=.055 ; 90 \%$ confidence intervals .046 .064). These values fall slightly below the ideal thresholds (the CFI should be above .9), but are comparable with findings within other studies of similarly sized samples (Maroufizadeh et al., 2016).

Table 2: Reliability statistics for locus of control scales and subscales

\begin{tabular}{lll}
\hline Scale/subscale & Version & Cronbach's alpha \\
\hline \multirow{2}{*}{ Full scale } & Original & .737 \\
\cline { 2 - 3 } & Gaming & .728 \\
\hline \multirow{2}{*}{ Internality subscale } & Original & .606 \\
\cline { 2 - 3 } & Gaming & .608 \\
\hline Chance subscale & Original & .811 \\
\cline { 2 - 3 } & Gaming & .740 \\
\hline Powerful others subscale & Original & .792 \\
\cline { 2 - 3 } & Gaming & .806 \\
\hline
\end{tabular}

Scores on the standard, 'real-world' locus of control scale correlated moderately ( $r$ values of .25 to .43 ) with scores on the novel version adapted to measure in-game perceptions of control, on each of the three subscales, as shown in Table 3. Repeated-measures t-tests identified no significant differences between real-world and in-game scores on the internality or chance subscales, but people felt significantly less under the control of 
'powerful others' in-game (mean rating of 17.26, SD 8.91) than in the real world (mean rating of 21.50, SD 8.42), even when applying a Bonferroni correction for multiple comparisons and setting the alpha at .017.

Table 3: Correlations and differences between real-world and in-game locus of control subscale scores

\begin{tabular}{|c|c|c|c|c|c|c|c|c|}
\hline \multirow[t]{2}{*}{ Subscale } & Real world & In-game & \multicolumn{3}{|c|}{ Correlation statistics } & \multicolumn{3}{|c|}{$\begin{array}{l}\text { Repeated-measures } \\
\text { t-test statistics }\end{array}$} \\
\hline & \multicolumn{2}{|c|}{ Mean (SD) } & $\mathrm{N}$ & $\mathrm{R}$ & $p$ & $d f$ & $\mathrm{~T}$ & $p$ \\
\hline Internality & $32.36(6.01)$ & $32.62(6.21)$ & 242 & .251 & $<.0005$ & 241 &.-541 & .589 \\
\hline Chance & 20.81 (8.79) & $20.49(8.24)$ & 243 & .434 & $<.0005$ & 242 & .566 & .571 \\
\hline Powerful others & $21.50(8.42)$ & $17.27(8.91)$ & 241 & .349 & $<.0005$ & 240 & 6.656 & $<.0005$ \\
\hline
\end{tabular}

Locus of control subscale scores and gaming involvement

As 
Table 4 shows, multiple linear regression analyses indicated that frequency of gaming was predicted by higher scores for the real-world powerful others subscale $\left(\beta=.220, \mathrm{sr}^{2}=.027\right.$ $p=.007)$, but by lower scores for the in-game powerful others score $\left(\beta=-.299, s^{2}=.055\right.$ $p<.0005)$, and by higher in-game internality scores $\left(\beta=.143, s r^{2}=.016, p=.040\right)$ (see model 1a). Problem gaming scores were predicted by higher scores on the real-world version of the powerful others subscale $\left(\beta=.211, \mathrm{sr}^{2}=.025, p=.014\right)$, but not by any of the in-game locus of control scores (model $1 b)$. 
Table 4 Regression models exploring locus of control scores as predictors of gaming involvement

\begin{tabular}{|c|c|c|c|c|c|c|c|c|}
\hline $\begin{array}{l}\text { Model \& } \\
\text { criterion }\end{array}$ & $\begin{array}{l}\text { Overall } \\
\text { model fit }\end{array}$ & Predictor variables & $\begin{array}{l}\text { Unstandard } \\
\text { ized beta }\end{array}$ & SE & $\begin{array}{l}\text { Standardi } \\
\text { zed beta }\end{array}$ & $\mathrm{T}$ & $\begin{array}{l}p \text { - } \\
\text { value }\end{array}$ & $s r^{2}$ \\
\hline \multirow{6}{*}{$\begin{array}{l}\text { 1a: } \\
\text { Frequency } \\
\text { of gaming }\end{array}$} & \multirow{6}{*}{$\begin{array}{l}F(6,216)=9 . \\
155 \\
p<.0005, \\
R^{2}=.203, R^{2} \\
\text { Adj=.181 } \\
\text { (SE 1.642) }\end{array}$} & RW internality & .000 & .022 & -.001 & -.014 & .989 & .000 \\
\hline & & RW chance & -.016 & .019 & -.076 & -.848 & .397 & .003 \\
\hline & & RW powerful others & .047 & .017 & .220 & 2.706 & .007 & .027 \\
\hline & & GW internality & .041 & .020 & .143 & 2.069 & .040 & .016 \\
\hline & & GW chance & -.032 & .019 & -.145 & -1.721 & .087 & .011 \\
\hline & & GW powerful others & -.061 & .016 & -.299 & -3.847 & $<.0005$ & .055 \\
\hline \multirow{6}{*}{$\begin{array}{l}\text { 1b: } \\
\text { Problem } \\
\text { gaming } \\
\text { score }\end{array}$} & \multirow{6}{*}{$\begin{array}{l}F(6,218)= \\
4.647, \\
p<.0005, \\
R^{2}=.113, R^{2} \\
\text { Adj }=.089 .\end{array}$} & RW internality & -.160 & .135 & -.089 & -1.187 & .237 & .006 \\
\hline & & RW chance & .011 & .115 & .009 & .094 & .925 & .000 \\
\hline & & RW powerful others & .268 & .108 & .211 & 2.472 & .014 & .025 \\
\hline & & GW internality & .225 & .123 & .132 & 1.827 & .069 & .014 \\
\hline & & GW chance & -.050 & .117 & -.038 & -.425 & .671 & .001 \\
\hline & & GW powerful others & .183 & .098 & .154 & 1.872 & .063 & .014 \\
\hline
\end{tabular}

$\mathrm{RW}=$ real world; GW = game world

In order to determine whether the contrast between real-world and in-game locus of control was important, regressions were repeated with three 'difference' scores for the three locus of control subscales. As seen in 
Table 5, model 2a, gaming frequency was predicted by feeling less governed by powerful others within the game world $\left(\beta=.309, \mathrm{sr}^{2}=.067, \mathrm{p}<.0005\right)$. Model $2 \mathrm{~b}$ was not quite significant overall, indicating that the locus of control difference scores as a whole do not account for a meaningful amount of variance in problem gaming, but a looking at predictor strength, it can be seen that greater sense of internality in-game was a significant predictor $\left(\beta=.167, \mathrm{sr}^{2}=.022, \mathrm{p}=.028\right)$. 
Table 5: Regression models exploring difference in real-world versus game world locus of control scores as predictors of gaming involvement

\begin{tabular}{|c|c|c|c|c|c|c|c|c|}
\hline $\begin{array}{l}\text { Model \& } \\
\text { criterion }\end{array}$ & $\begin{array}{l}\text { Overall } \\
\text { model fit }\end{array}$ & Predictor variables & $\begin{array}{l}\text { Unstandar } \\
\text { dized beta }\end{array}$ & SE & $\begin{array}{l}\text { Standard } \\
\text { ized beta }\end{array}$ & $T$ & $p$-value & $s r^{2}$ \\
\hline \multirow{3}{*}{$\begin{array}{l}\text { 2a: } \\
\text { Frequency } \\
\text { of gaming }\end{array}$} & \multirow{3}{*}{$\begin{array}{l}F(3,219)= \\
10.436, \\
p<.0005, \\
R^{2}=.125, R^{2} \\
\text { Adj=.113. }\end{array}$} & $\begin{array}{l}\text { Feel greater sense of } \\
\text { internality in-game }\end{array}$ & .019 & .018 & .076 & 1.067 & .287 & .004 \\
\hline & & $\begin{array}{l}\text { Feel less governed by } \\
\text { powerful others in- } \\
\text { game }\end{array}$ & .056 & .014 & .309 & 4.099 & $<.0005$ & .067 \\
\hline & & $\begin{array}{l}\text { Feel less governed by } \\
\text { chance in-game }\end{array}$ & .004 & .016 & .021 & .258 & .796 & .000 \\
\hline \multirow{3}{*}{$\begin{array}{l}\text { 2b: } \\
\text { Problem } \\
\text { gaming } \\
\text { score }\end{array}$} & \multirow{3}{*}{$\begin{array}{l}F(3,221)= \\
2.589, \\
p=.054, R^{2}= \\
.034, R^{2} \\
\text { Adj }=.021 .\end{array}$} & $\begin{array}{l}\text { Feel greater sense of } \\
\text { internality in-game }\end{array}$ & .237 & .107 & .167 & 2.216 & .028 & .022 \\
\hline & & $\begin{array}{l}\text { Feel less governed by } \\
\text { powerful others in- } \\
\text { game }\end{array}$ & .012 & .085 & .011 & .139 & .889 & .000 \\
\hline & & $\begin{array}{l}\text { Feel less governed by } \\
\text { chance in-game }\end{array}$ & .029 & .099 & .025 & .295 & .769 & .000 \\
\hline
\end{tabular}

A principle components analysis on the positive gaming items from the Game Experience Questionnaire identified two clear factors, relating to positive affect while gaming, and positive affect post-gaming, with Cronbach's alpha values of .92 and .85, respectively. As shown in Table 6, the regressions testing whether differential locus of control scores were associated with greater enjoyment of gaming indicated that positive affect during gaming was predicted by lower powerful others scores in-game than in the real world $(\beta=.225$, $\mathrm{sr}^{2}=.036, \mathrm{p}=.004$ ) (model 3a). Positive affect after gaming was not significantly predicted by any of the differential locus of control scores (model 3b). 
Table 6: Regression models testing whether difference in real world versus game-world locus of control scores predict gaming enjoyment

\begin{tabular}{|c|c|c|c|c|c|c|c|c|}
\hline $\begin{array}{l}\text { Model } \\
\& \\
\text { criterion }\end{array}$ & $\begin{array}{l}\text { Overall } \\
\text { model fit }\end{array}$ & Predictor variables & $\begin{array}{l}\text { Unstand } \\
\text { ardized } \\
\text { beta }\end{array}$ & SE & $\begin{array}{l}\text { Standa } \\
\text { rdized } \\
\text { beta }\end{array}$ & $\mathrm{T}$ & $p$-value & $s r^{2}$ \\
\hline \multirow{3}{*}{$\begin{array}{l}\text { 3a: } \\
\text { Positive } \\
\text { affect } \\
\text { in-game }\end{array}$} & \multirow{3}{*}{$\begin{array}{l}F(3,224)= \\
2.962, \\
p=.033, R^{2}= \\
.038, R^{2} \\
\text { Adj }=.025 .\end{array}$} & $\begin{array}{l}\text { Feel greater sense of } \\
\text { internality in-game }\end{array}$ & .012 & .035 & .025 & .336 & .737 & 0.000 \\
\hline & & $\begin{array}{l}\text { Feel less governed by } \\
\text { powerful others in-game }\end{array}$ & .080 & .028 & .225 & 2.889 & .004 & 0.036 \\
\hline & & $\begin{array}{l}\text { Feel less governed by } \\
\text { chance in-game }\end{array}$ & -.040 & .033 & -.103 & -1.237 & .217 & 0.007 \\
\hline \multirow{3}{*}{$\begin{array}{l}\text { 3b: } \\
\text { Positive } \\
\text { affect } \\
\text { post- } \\
\text { game }\end{array}$} & \multirow{3}{*}{$\begin{array}{l}F(3,220)= \\
0.545, \\
p=.652, R^{2}= \\
.007, R^{2} \\
\text { Adj=-.006. }\end{array}$} & $\begin{array}{l}\text { Feel greater sense of } \\
\text { internality in-game }\end{array}$ & -.018 & .057 & -.024 & -.310 & .757 & .000 \\
\hline & & $\begin{array}{l}\text { Feel less governed by } \\
\text { powerful others in-game }\end{array}$ & .042 & .045 & .075 & .931 & .353 & .004 \\
\hline & & $\begin{array}{l}\text { Feel less governed by } \\
\text { chance in-game }\end{array}$ & .016 & .055 & .026 & .294 & .769 & .000 \\
\hline
\end{tabular}

When positive affect during-game and post-game were added alongside differential locus of control scores in the models predicting gaming involvement (i.e. expanding models $2 \mathrm{a}$ and $2 b)$, the positive affect scores improved the models' predictive power ( $R^{2}$ improved from .125 to .268 when predicting frequency, and from .034 to .089 when predicting problem gaming), but the locus of control measures that were significant in models $2 \mathrm{a}$ and $2 \mathrm{~b}$ also remained significant, contributing unique explanation of the variance. As shown in Table 7, gaming frequency was predicted both by feeling less governed by powerful others in-game $\left(\beta=.226, s r^{2}=.033, p=.002\right)$, and by in-game positive affect $\left(\beta=.427, s r^{2}=.108, p<.0005\right)$ (model 4a). Problem gaming was predicted by feeling a greater sense of internality within the game world $\left(\beta=.205, s r^{2}=.031, p=.008\right)$, and also by positive affect post-game $\left(\beta=.252, s r^{2}=.038\right.$, $\mathrm{p}=.003)$ (model 4b). 
Table 7: Regression models predicting gaming involvement by differences in real-world and game-world locus of control scores, and positive gaming experiences

\begin{tabular}{|c|c|c|c|c|c|c|c|c|}
\hline $\begin{array}{l}\text { Model \& } \\
\text { criterion }\end{array}$ & $\begin{array}{l}\text { Overall } \\
\text { model fit }\end{array}$ & Predictor variables & $\begin{array}{l}\text { Unstand } \\
\text { ardized } \\
\text { beta }\end{array}$ & SE & $\begin{array}{l}\text { Standa } \\
\text { rdized } \\
\text { beta }\end{array}$ & $T$ & $\begin{array}{l}\mathrm{p}- \\
\text { value }\end{array}$ & sr2 \\
\hline \multirow{5}{*}{$\begin{array}{l}\text { 4a: } \\
\text { Frequency } \\
\text { of gaming }\end{array}$} & \multirow{5}{*}{$\begin{array}{l}F(5,209)= \\
15.322 \\
P<.0005 \\
R^{2}=.268 \\
R^{2} \\
\text { Adj }=.251\end{array}$} & $\begin{array}{l}\text { Feel greater sense of } \\
\text { internality in-game }\end{array}$ & .015 & .016 & .061 & .886 & .377 & .003 \\
\hline & & $\begin{array}{l}\text { Feel less governed by } \\
\text { powerful others in-game }\end{array}$ & .041 & .013 & .226 & 3.095 & .002 & .033 \\
\hline & & $\begin{array}{l}\text { Feel less governed by } \\
\text { chance in-game }\end{array}$ & .009 & .016 & .047 & .585 & .559 & .001 \\
\hline & & In-game positive affect & .224 & .040 & .427 & 5.565 & .000 & .108 \\
\hline & & Post-game positive affect & -.016 & .024 & -.048 & -.638 & .524 & .001 \\
\hline \multirow{5}{*}{$\begin{array}{l}\text { 4b: } \\
\text { Problem } \\
\text { gaming } \\
\text { score }\end{array}$} & \multirow{5}{*}{$\begin{array}{l}F(5,212)= \\
4.131 \\
p=.001 \\
R^{2}=.089 \\
R^{2} \\
\text { Adj }=.067\end{array}$} & $\begin{array}{l}\text { Feel greater sense of } \\
\text { internality in-game }\end{array}$ & .289 & .108 & .205 & 2.674 & .008 & .031 \\
\hline & & $\begin{array}{l}\text { Feel less governed by } \\
\text { powerful others in-game }\end{array}$ & .045 & .088 & .042 & .515 & .607 & .001 \\
\hline & & $\begin{array}{l}\text { Feel less governed by } \\
\text { chance in-game }\end{array}$ & -.062 & .106 & -.052 & -.589 & .556 & .002 \\
\hline & & In-game positive affect & -.161 & .271 & -.051 & -.595 & .553 & .002 \\
\hline & & Post-game positive affect & .488 & .163 & .252 & 2.994 & .003 & .038 \\
\hline
\end{tabular}

\section{Game genres, gaming frequency, and locus of control}

Single-player and multi-player game ratings for each genre were highly correlated $(r=.50$ to .82) for all but role-play games, so before entering genre data into a regression model, single- and multi- player responses for each genre (except role-play games) were merged, taking the highest rating out of the two formats. The resulting game genre preference scores were then entered into regression models $5 a-5 c$, along with overall gaming frequency (to ensure relationships between genre preferences and criterion variables were not simply artefacts of differential frequency of gaming by those preferring particular genres). As shown in Table 8, model 5a, single-player role-play game preference was the only significant predictor of in-game internality $\left(\beta=.214, s r^{2}=.026, p=.009\right)$. 
Table 8: Game genre preferences and gaming frequency as predictors of in-game internality scores

\begin{tabular}{|c|c|c|c|c|c|c|c|c|}
\hline $\begin{array}{l}\text { Model \& } \\
\text { criterion }\end{array}$ & $\begin{array}{l}\text { Overall } \\
\text { model fit }\end{array}$ & Predictor variables & $\begin{array}{l}\text { Unstan } \\
\text { dardize } \\
\text { d beta }\end{array}$ & SE & $\begin{array}{l}\text { Standar } \\
\text { dized } \\
\text { beta }\end{array}$ & $\mathrm{T}$ & $\mathrm{p}$-value & $s r^{2}$ \\
\hline \multirow{11}{*}{$\begin{array}{l}5 a: \text { In- } \\
\text { game } \\
\text { internalit } \\
\text { y }\end{array}$} & \multirow{11}{*}{$\begin{array}{l}F(11,219) \\
=4.440, \\
p<.0005, \\
R^{2}=.181, \\
R^{2} \\
\text { Adj=.140. }\end{array}$} & First person shooters & .165 & .251 & .058 & .660 & .510 & 0.002 \\
\hline & & Adventure games & .233 & .256 & .080 & .910 & .364 & 0.003 \\
\hline & & Music games & .006 & .202 & .002 & .029 & .977 & 0.000 \\
\hline & & Fighting games & .120 & .190 & .044 & .632 & .528 & 0.002 \\
\hline & & Quiz games & -.258 & .213 & -.082 & -1.212 & .227 & 0.005 \\
\hline & & Strategy games & .234 & .191 & .091 & 1.225 & .222 & 0.006 \\
\hline & & Sports games & .047 & .189 & .017 & .249 & .804 & 0.000 \\
\hline & & Roleplay games (SP) & .565 & .214 & .214 & 2.645 & .009 & 0.026 \\
\hline & & Roleplay games (MP) & .148 & .179 & .055 & .831 & .407 & 0.003 \\
\hline & & Colocation games & -.018 & .229 & -.005 & -.079 & .937 & 0.000 \\
\hline & & Gaming frequency & .206 & .268 & .058 & .767 & .444 & 0.002 \\
\hline
\end{tabular}

$\mathrm{SP}=$ Single player; $\mathrm{MP}=$ multi-player .

As shown in Table 9, model 5b, gaming frequency $\left(\beta=-.170, s r^{2}=.018, p=.022\right)$ and sports game preference scores $\left(\beta=-.185 \mathrm{sr}^{2}=.027, \mathrm{p}=.007\right)$ were both significant inverse predictors of in-game chance.

Table 9: Game genre preferences and gaming frequency as predictors of in-game chance locus of control scores

\begin{tabular}{|c|c|c|c|c|c|c|c|c|}
\hline $\begin{array}{l}\text { Model \& } \\
\text { criterion }\end{array}$ & $\begin{array}{l}\text { Overall } \\
\text { model fit }\end{array}$ & Predictor variables & $\begin{array}{l}\text { Unstan } \\
\text { dardize } \\
\text { d beta }\end{array}$ & SE & $\begin{array}{c}\text { Standar } \\
\text { dized } \\
\text { beta }\end{array}$ & $T$ & $p$-value & $s r^{2}$ \\
\hline \multirow{11}{*}{$\begin{array}{l}\text { 5b: In- } \\
\text { game } \\
\text { chance }\end{array}$} & \multirow{11}{*}{$\begin{array}{l}F(11,220) \\
=5.224, \\
p<.0005, \\
R^{2}=.207, \\
R^{2} \\
\text { Adj }=.167\end{array}$} & First person shooters & -.197 & .324 & -.053 & -.608 & .544 & 0.001 \\
\hline & & Adventure games & -.112 & .326 & -.030 & -.343 & .732 & 0.000 \\
\hline & & Music games & -.056 & .258 & -.015 & -.217 & .828 & 0.000 \\
\hline & & Fighting games & -.098 & .244 & -.027 & -.404 & .687 & 0.001 \\
\hline & & Quiz games & -.300 & .272 & -.073 & -1.100 & .272 & 0.004 \\
\hline & & Strategy games & -.319 & .243 & -.096 & -1.312 & .191 & 0.006 \\
\hline & & Sports games & -.657 & .242 & -.185 & -2.712 & .007 & 0.027 \\
\hline & & Roleplay games (SP) & -.489 & .269 & -.145 & -1.819 & .070 & 0.012 \\
\hline & & Roleplay games (MP) & .422 & .229 & .119 & 1.840 & .067 & 0.012 \\
\hline & & Colocation games & .513 & .297 & .119 & 1.729 & .085 & 0.008 \\
\hline & & Gaming frequency & -.793 & .343 & -.170 & -2.309 & .022 & 0.018 \\
\hline
\end{tabular}

$\mathrm{SP}=$ Single player $; \mathrm{MP}=$ multi-player .

As shown in Table 10, model 5c, in-game powerful others score was predicted by multiplayer roleplay game preference $\left(\beta=.155, s r^{2}=.021, p=.021\right)$ and by gaming frequency $(\beta=-$ $\left..349, \mathrm{sr}^{2}=.078, \mathrm{p}<.0005\right)$. 
Table 10: Game genre preferences and gaming frequency as predictors of in-game powerful others locus of control scores

\begin{tabular}{|c|c|c|c|c|c|c|c|c|}
\hline $\begin{array}{l}\text { Model \& } \\
\text { criterion }\end{array}$ & $\begin{array}{l}\text { Overall } \\
\text { model fit }\end{array}$ & Predictor variables & $\begin{array}{l}\text { Unstan } \\
\text { dardize } \\
\text { d beta }\end{array}$ & SE & $\begin{array}{c}\text { Standar } \\
\text { dized } \\
\text { beta } \\
\end{array}$ & $\mathrm{T}$ & $p$-value & $s r^{2}$ \\
\hline \multirow{11}{*}{$\begin{array}{l}5 c \text { : In- } \\
\text { game } \\
\text { powerful- } \\
\text { others }\end{array}$} & \multirow{11}{*}{$\begin{array}{l}F(11,217)= \\
4.135 \\
p<.0005 \\
R^{2}=.173 \\
R^{2} \\
\text { Adj }=.131\end{array}$} & First person shooters & .355 & .352 & .089 & 1.010 & .314 & 0.004 \\
\hline & & Adventure games & -.216 & .358 & -.054 & -.602 & .548 & 0.001 \\
\hline & & Music games & .118 & .281 & .030 & .419 & .676 & 0.001 \\
\hline & & Fighting games & -.043 & .270 & -.011 & -.159 & .874 & 0.000 \\
\hline & & Quiz games & .044 & .302 & .010 & .145 & .885 & 0.000 \\
\hline & & Strategy games & .079 & .271 & .022 & .292 & .771 & 0.000 \\
\hline & & Sports games & -.497 & .265 & -.130 & -1.874 & .062 & 0.013 \\
\hline & & Roleplay games (SP) & -.295 & .300 & -.081 & -.984 & .326 & 0.004 \\
\hline & & Roleplay games (MP) & .585 & .252 & .155 & 2.326 & .021 & 0.021 \\
\hline & & Colocation games & .176 & .321 & .038 & .548 & .584 & 0.001 \\
\hline & & Gaming frequency & -1.728 & .382 & -.349 & -4.530 & $<.0005$ & 0.078 \\
\hline
\end{tabular}

$\mathrm{SP}=$ Single player; $\mathrm{MP}=$ multi-player .

\section{Discussion}

This study explored relationships between gaming frequency, gaming enjoyment, and problematic gaming; and locus of control - as experienced in both the real-world and the gaming environment. Scores on the adapted version of the Levenson (1981) locus of control scale that we modified to refer the gaming world were moderately correlated with those on the traditional, 'real-world' version, but there was also a significant difference between the two in terms of 'powerful others' scores, with people feeling significantly less under the control of powerful others in the gaming world. This indicates that although people's locus of control in the game world is, on the whole, correlated with their typical locus of control in the real world (consistent with hypothesis 2 ), the two are not entirely synonymous (consistent with hypothesis 3), and feelings about powerful others, in particular, seem to diverge across environments - with a less 'external' locus of control in-game than in the real world.

Problem gaming scores correlated moderately with gaming frequency, indicating that although they were linked, they also captured distinct aspects of involvement. This is consistent with Király et al's (2017) finding of a low to modest correlation between time spent gaming and problem gaming scores in a sample of over 5,000 online gamers (Király et al., 2017), and supports the idea that we cannot infer problematic gaming purely based on high involvement. We therefore explored links between locus of control and both measures 
of involvement, to determine whether one, the other, or both, were linked to particular locus of control.

In terms of scores on the original, real-world version of the locus of control scale, we observed that higher 'powerful others' ratings predicted both gaming frequency and problem gaming $\left(\beta=.220, s r^{2}=.027\right)$. This is consistent with previous studies' findings (Koo, 2009), and with our hypothesis 1 . For the in-game version of the scale, by contrast, lower 'powerful others' scores $\left(\beta=-.299, s r^{2}=.055\right)$, along with higher 'internality' scores $(\beta=.143$, $\left.s r^{2}=.016\right)$ predicted gaming frequency, consistent with our hypothesis 5; that people may be drawn to videogames because they provide an arena in which they can feel more in control. To further test the idea that it is increased control in-game compared with in real life that matters, we looked at how well the difference between people's locus of control scores across environments predicted gaming involvement. We found that feeling less governed by powerful others in-game than in the real world predicted gaming frequency $(\beta=.309$, $\left.s r^{2}=.067\right)$, while feeling a greater sense of internality in-game than in the real-world predicted problem gaming $\left(\beta=.167, \mathrm{sr}^{2}=.022\right)$.

This latter effect could be compared with Kardefelt-Winther's (2014) finding, when looking at a subsample of participants who had experienced more negative outcomes due to gaming, that escapism was linked with negative outcomes selectively in people who were low on self-esteem or high on stress (importantly; stress in this study was measured by items referring to feeling lack of control; (Kardefelt-Winther, 2014)). In other words, enjoying gaming as a form of escapism is not necessarily a bad thing; but may be linked with negative outcomes when it is symptomatic of needing to escape from particularly negative feelings, such as feeling out of control. In the current study, simply experiencing a strong sense of internality in-game predicts frequency of play but not problematic play, i.e. it is not 'bad' per se to enjoy a sense of internal control when playing videogames. However, the degree to which you feel disproportionately in-control in a videogame compared with in your daily life, is what appears to be associated with problematic gaming. While this is intuitively plausible, given the small magnitude of the effect sizes that we observed, our findings must be interpreted with caution, pending replication in larger and more representative samples. 
When adding measures of gaming enjoyment to the equation, we found that the locus of control-related predictors remained significant, highlighting that their link with gaming frequency and problematic gaming is more complex than simply making gaming more enjoyable. Factors such as a sense of achievement, for example, which other studies have identified as a motivating factor associated with excessive gaming (Dauriat et al., 2011; Kuss et al., 2012); could contribute to the heightened involvement in gaming by those who feel greater control in-game.

Interestingly, gaming frequency was linked to feeling positive while gaming $(\beta=.427$, $\left.s r^{2}=.108\right)$, whereas problem gaming scores were linked to feeling positive after gaming $\left(\beta=.252, s r^{2}=.038\right)$. This is consistent with a study of adolescent MMORPG players which found that when they were able to game, 'addicted' players experienced a 'relief from dissatisfaction', whereas non-addicted players experienced 'satisfaction' (Wan and Chiou, 2006). However, while some of the items used in the current study to measure positive post-game feelings could, arguably, be linked with relief from craving (e.g. feeling 'revived' or 'satisfied'), several refer to concepts that are not intuitively consistent with this hypothesis (i.e. feeling 'victorious', 'powerful' and 'proud'). The extent to which a person's enjoyment of gaming comes from relief from craving, versus pleasure in the activity itself, could be a key factor in identifying problematic gamers, and future studies into gaming experiences may find it valuable to disentangle the two, when measuring gaming enjoyment.

It is also possible that the effect is driven by different motivations for gaming amongst those who are high versus low on problem gaming symptoms. In both the gambling research (Yi et al., 2015) and the alcohol use disorder literature (Mann et al., 2018), a distinction has been drawn between those who gamble or drink for reward, and those who engage in these behaviours for relief; and motivations related to coping and escapism are particularly linked with problematic behaviours (Lloyd et al., 2010). This brings us back to the theory discussed above, that gaming as a means of feeling increased control may be problematic in people who are experiencing stress, or high external locus of control, in their everyday lives.

In terms of the link between locus of control and different gaming genres, we identified that preference for single-player roleplay games was associated with greater internality in-game $\left(\beta=.214, s r^{2}=.026\right)$, whereas preference for multi-player roleplay games was linked with 
higher feelings of 'powerful others' having control in-game $\left(\beta=.155, s r^{2}=.021\right)$. This makes intuitive sense, as single-player roleplay games do afford the player a large amount of control over their environment. Within massively multiplayer online roleplay games, by contrast, individual roles and status can and do differ (Castronova, 2008b), and the player is faced with increased variability in outcomes, associated with other people (rather than simply artificial intelligence).

The only other game genre to predict of locus of control scores was sports; with a preference for sports games being linked with lower perceptions of the role of 'chance' ingame $\left(\beta=-.185 \mathrm{sr}^{2}=.027\right)$. This could be because sports games outcomes appear less chancedriven, and this impacts on the way those who play these games in particular perceive chance in the gaming world, but this is a preliminary and unexpected finding that needs replication before we can begin to draw strong conclusions.

A limitation of this study is the relatively small sample size, and the reliance upon a convenience sample, meaning that we cannot know how representative of the gaming community as a whole our results are. However, the basic demographic characteristics of our sample (39\% female with a mean age of 29 years) are comparable with those of gamers in a recent large-scale prevalence survey ( $40 \%$ female with a mean age of 32.6 years) (Wittek et al., 2016).

Other potential limitations relate to the measures used in the questionnaire. While we measured gaming frequency and genre preferences with a pre-validated scale (Manero et al., 2016), frequency was rated on a Likert scale, where the maximum response option was 'daily' play. While this is likely to give a reasonable measure of frequency variability within the sample, it may not give an accurate representation of the amount of play engaged in by those who do not play daily, but who 'binge' play for many hours at a time at weekends, for example. The measures of enjoyment while gaming and post-gaming were all made retrospectively, and thus subject to bias in memory. Ideally, measures of affect taken immediately during and post-gaming would provide a more reliable estimate of gamers' positive experiences of gaming

The degree of similarity between the original and game-world versions of the locus of control scales could have allowed participants to guess the purpose of the study, and 
consciously or subconsciously, demand characteristics may have influenced their responses. The use of block randomization means that this would not have disproportionately influenced responses on one version of the scale, but does not remove the potential for bias influencing the data. The development of a novel scale designed specifically to assess ingame locus of control would be a valuable addition to the literature, to allow more subtle measurement of this phenomenon. The fact that the confirmatory factor analysis results were only bordering on acceptable is further reason for recommending a novel scale for tailored assessment of gaming-related locus of control (though the relatively small convenience sample used in the current study could have also contributed to the less than ideal psychometric properties observed).

A final limitation, common to all cross-sectional research, is the lack of ability to infer direction of causality in the results. While it seems logical to deduce that feeling more control in-game encourages people to play games more frequently, it is also possible that people who play games more frequently go on to develop a greater sense of control ingame than those who play infrequently. Longitudinal research observing whether an individual's locus of control in-game is constant over time, or whether it becomes more internal as they spend more time playing, would be needed to gain insight into this possibility.

This study has, nevertheless, identified some important phenomena. Firstly, we have demonstrated that a person's locus of control within the videogame environment can diverge from their locus of control profile in the real world. Secondly, we have seen that this can be linked with greater enjoyment of gaming. And thirdly, we observed that those for whom this effect is particularly pronounced may be more likely to spend a lot of time gaming, and possibly experience difficulties with their gaming. Further research is needed to empirically test the question of whether enjoyment of greater feelings of control within videogames is potentially detrimental, or whether the link is purely correlational. It is also possible that the ability to experience a more pleasurable and satisfying locus of control ingame could be beneficial. A recent study (Johnson et al., 2016) found that measures of need-satisfaction (competence, autonomy and relatedness) were all linked with amount of time spent gaming, and suggested that this supports the idea that gaming can be a positive experience, and an arena in which people can satisfy psychological needs. Understanding 
the subtleties underlying the growing appeal of videogames also has potential applications entirely outside of the gaming environment, with Castronova (2008a, 2008b) arguing that insights from game design, and how people interact with games, have considerable potential to inform public policy within the real world.

\section{Declaration of Competing Interests}

The Authors declare that there is no conflict of interest.

\section{Funding}

This research received no specific grant from any funding agency in the public, commercial, or not-for-profit sectors.

\section{References}

Aarseth E, Bean AM, Boonen H, et al. (2016) Scholars' open debate paper on the World Health Organization ICD-11 Gaming Disorder proposal. Journal of Behavioral Addictions: 1-4. DOI: 10.1556/2006.5.2016.088.

Adachi PJC and Willoughby T (2017) The Link Between Playing Video Games and Positive Youth Outcomes. Child Development Perspectives 11(3): 202-206. DOI: 10.1111/cdep.12232.

Auer M and Griffiths MD (2017) Self-Reported Losses Versus Actual Losses in Online Gambling: An Empirical Study. Journal of Gambling Studies 33(3). Springer US: 795-806. DOI: 10.1007/s10899-016-9648-0.

Browne BA and Brown DJ (1994) Predictors of Lottery Gambling Among American College Students. The Journal of Social Psychology 134(3): 339-347. DOI: 10.1080/00224545.1994.9711738.

Castronova E (2008a) Exodus to the Virtual World: How Online Fun is Changing Reality. New York: Palgrave Macmillan.

Castronova E (2008b) Synthetic worlds: The business and culture of online games. Chicago: University of Chicago Press.

Chak K and Leung L (2004) Shyness and Locus of Control as Predictors of Internet Addiction and Internet Use. CyberPsychology \& Behavior 7(5): 559-570. DOI: 10.1089/cpb.2004.7.559.

Dauriat FZ, Zermatten A, Billieux J, et al. (2011) Motivations to Play Specifically Predict Excessive 
Involvement in Massively Multiplayer Online Role-Playing Games: Evidence from an Online Survey. European Addiction Research 17(4): 185-189. DOI: 10.1159/000326070.

Demetrovics Z, Urbán R, Nagygyörgy K, et al. (2012) The Development of the Problematic Online Gaming Questionnaire (POGQ). Laks J (ed.) PLOS ONE 7(5): e36417. DOI: 10.1371/journal.pone.0036417.

Dudgeon P (2016) A Comparative Investigation of Confidence Intervals for IndependentVariables in Linear Regression. Multivariate Behavioral Research 51(2-3): 139-153. DOI:

10.1080/00273171.2015.1121372.

Griffiths MD, van Rooij AJ, Kardefelt-Winther D, et al. (2016) Working towards an international consensus on criteria for assessing internet gaming disorder: A critical commentary on Petry et al. (2014). Addiction 111(1): 167-175. DOI: 10.1111/add.13057.

Haynes P and Ayliffe G (1991) Locus of control of behaviour: is high externality associated with substance misuse? British journal of addiction 86(9): 1111-7. Available at: http://www.ncbi.nlm.nih.gov/pubmed/1932882.

Hou J, Ndasauka Y, Jiang Y, et al. (2017) Excessive use of WeChat, social interaction and locus of control among college students in China. Yuan T (ed.) PLOS ONE 12(8): e0183633. DOI: 10.1371/journal.pone.0183633.

IJsselsteijn WA, Poels K and de Kort YAW (2013) The Game Experience Questionnaire. Eindhoven: Technische Universiteit Eindhoven. Available at: https://pure.tue.nl/ws/portalfiles/portal/21666907.

İskender M and Akin A (2010) Social self-efficacy, academic locus of control, and internet addiction. Computers \& Education 54: 1101-1106. DOI: 10.1016/j.compedu.2009.10.014.

Johnson D, Gardner J and Sweetser P (2016) Motivations for videogame play: Predictors of time spent playing. Computers in Human Behavior 63: 805-812. DOI: 10.1016/j.chb.2016.06.028.

Kardefelt-Winther D (2014) The moderating role of psychosocial well-being on the relationship between escapism and excessive online gaming. Computers in Human Behavior 38: 68-74. DOI: 10.1016/j.chb.2014.05.020.

King D, Delfabbro P and Griffiths M (2010) Video game structural characteristics: A new psychological taxonomy. International Journal of Mental Health and Addiction 8(1): 90-106. DOI: 10.1007/s11469-009-9206-4. 
Király O, Nagygyörgy K, Koronczai B, et al. (2015) Assessment of problematic Internet use and online video gaming. Mental health in the digital age: Grave dangers, great promise.: 46-68. DOI: 10.1093/med/9780199380183.003.0003.

Király O, Tóth D, Urbán R, et al. (2017) Intense video gaming is not essentially problematic. Psychology of Addictive Behaviors 31(7): 807-817. DOI: 10.1037/adb0000316.

Koo D-M (2009) The moderating role of locus of control on the links between experiential motives and intentions to play online games. Computers in Human Behavior Computers(25): 466-474. DOI: $10.1016 / j . c h b .2008 .10 .010$.

Kourmousi N, Xythali V and Koutras V (2015) Reliability and Validity of the Multidimensional Locus of Control IPC Scale in a Sample of 3668 Greek Educators. Social Sciences 4(4): 1067-1078. DOI: $10.3390 /$ socsci4041067.

Kuss DJ, Louws J and Wiers RW (2012) Online Gaming Addiction? Motives Predict Addictive Play Behavior in Massively Multiplayer Online Role-Playing Games. Cyberpsychology, Behavior, and Social Networking 15(9): 480-485. DOI: 10.1089/cyber.2012.0034.

Kuss DJ, Griffiths MD and Pontes HM (2017) Chaos and confusion in DSM-5 diagnosis of Internet Gaming Disorder: Issues, concerns, and recommendations for clarity in the field. Journal of Behavioral Addictions 6(2): 103-109. DOI: 10.1556/2006.5.2016.062.

Laconi S, Pirès S and Chabrol H (2017) Internet gaming disorder, motives, game genres and psychopathology. Computers in Human Behavior 75: 652-659. DOI: 10.1016/j.chb.2017.06.012.

Lam D and Mizerski D (2005) The effects of locus of control on word-of-mouth communication. Journal of Marketing Communications 11(3): 215-228. DOI: 10.1080/1352726042000333180.

Levenson H (1981) Differentiating Among Internality, Powerful Others, and Chance. Research with the Locus of Control Construct: 15-63. DOI: 10.1016/B978-0-12-443201-7.50006-3.

Li J, Lepp A and Barkley JE (2015) Locus of control and cell phone use: Implications for sleep quality, academic performance, and subjective well-being. Computers in Human Behavior 52: 450-452. DOI: 10.1016/j.chb.2015.06.021.

Lloyd J, Doll H, Hawton K, et al. (2010) Internet Gamblers: A Latent Class Analysis of Their Behaviours and Health Experiences. Journal of Gambling Studies 26(3). DOI: 10.1007/s10899-010-9188-y.

Manero B, Torrente J, Freire M, et al. (2016) An instrument to build a gamer clustering framework according to gaming preferences and habits. Computers in Human Behavior 62: 353-363. DOI: 
10.1016/j.chb.2016.03.085.

Mann K, Roos CR, Hoffmann S, et al. (2018) Precision Medicine in Alcohol Dependence: A Controlled Trial Testing Pharmacotherapy Response among Reward and Relief Drinking Phenotypes. Neuropsychopharmacology 43(4): 891-899. DOI: 10.1038/npp.2017.282.

Maroufizadeh S, Omani Samani R, Amini P, et al. (2016) Factor structure, reliability, and validity of the Levenson's Locus of Control Scale in Iranian infertile people. Journal of health psychology: 1359105316666659. DOI: https://dx.doi.org/10.1177/1359105316666659.

Murray CD, Fox J and Pettife S (2007) Absorption, Dissociation, Locus of Control and Presence in Virtual Reality. Computers in Human Behavior 23(3): 1347-1354. DOI: 10.1017/СВ09781107415324.004.

Norman KL (2013) Geq (game engagement/experience questionnaire): a review of two papers. Interacting with Computers: 278-283.

Park N, Kim YC, Shon HY, et al. (2013) Factors influencing smartphone use and dependency in South Korea. Computers in Human Behavior 29(4): 1763-1770. DOI: 10.1016/j.chb.2013.02.008.

Rogers R, Dillman Carpentier FR and Barnard L (2016) Media enjoyment as a function of control over characters. Entertainment Computing 12: 29-39. DOI: 10.1016/j.entcom.2015.11.002.

Subramaniam M, Chua BY, Abdin E, et al. (2016) Prevalence and correlates of internet gaming problem among internet users: Results from an internet survey. Annals of the Academy of Medicine Singapore 45(5): 174-183.

Tabachnik, B. G. and Fidell LS (2001) Using multivariate statistics.

Wan C-S and Chiou W-B (2006) Psychological Motives and Online Games Addiction: ATest of Flow Theory and Humanistic Needs Theory for Taiwanese Adolescents. CyberPsychology \& Behavior 9(3): 317-324. DOI: 10.1089/cpb.2006.9.317.

Wittek CT, Finserås TR, Pallesen S, et al. (2016) Prevalence and Predictors of Video Game Addiction: A Study Based on a National Representative Sample of Gamers. International Journal of Mental Health and Addiction 14(5): 672-686. DOI: 10.1007/s11469-015-9592-8.

Yi S, Stewart M, Collins P, et al. (2015) The Activation of Reward Versus Relief Gambling Outcome Expectancies in Regular Gamblers: Relations to Gambling Motives. Journal of Gambling Studies 31(4): 1515-1530. DOI: 10.1007/s10899-014-9474-1. 